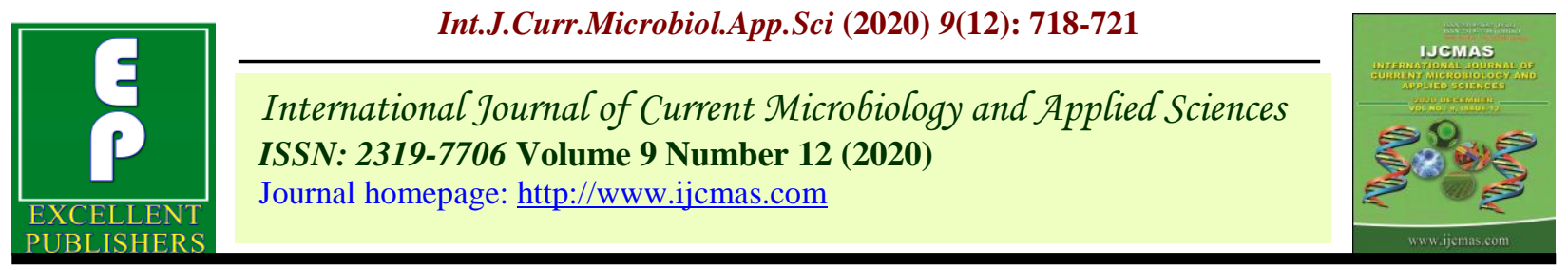

Case Study

https://doi.org/10.20546/ijcmas.2020.912.086

\title{
One Health Approach in Investigation of Human Brucellosis: A Case Report and its Investigation
}

\author{
A. Sundar ${ }^{1 *}$, S. Rajagunalan ${ }^{1}$, S. Malmarugan ${ }^{1}$, R. Sangameswaran ${ }^{2}$ and D.K. Sinha ${ }^{3}$ \\ ${ }^{1}$ Department of Veterinary Public Health and Epidemiology, ${ }^{2}$ Department of Veterinary and \\ Animal Husbandry Extension, Veterinary College and Research Institute, Tirunelveli, \\ TANUVAS, India \\ ${ }^{3}$ Division of Epidemiology, IVRI, Izatnagar, India \\ *Corresponding author
}

\section{A B S T R A C T}

\begin{tabular}{|c|}
\hline Keywords \\
\hline $\begin{array}{l}\text { One health } \\
\text { approach, Human } \\
\text { brucellosis, } \\
\text { Cervical } \\
\text { lymphadenopathy, } \\
\text { Occupational risk }\end{array}$ \\
\hline Article Info \\
\hline $\begin{array}{l}\text { Accepted: } \\
07 \text { November } 2020 \\
\text { Available Online: } \\
10 \text { December } 2020\end{array}$ \\
\hline
\end{tabular}

\section{Introduction}

Brucellosis is essentially a disease of animals, caused by bacterium of the genus Brucella with humans acting as an accidental host (Corbel, 2000). Brucella is an non-motile, non-encapsulated, facultative intracellular, Gram-negative coccobacillus. Among Brucella species, B. melitensis and B. suis are more virulent for humans than $B$. abortus and B. canis (Corbel, 2000; Mantur et al., 2007; Acha et al., 2011). The symptoms and clinical signs most commonly reported in humans are

\begin{abstract}
Brucellosis is an important zoonotic disease, affecting high-risk occupational groups who are in close contact with animals. This report describes a young field veterinarian who suffered from high fever, night sweat, chills, myalgia, tremors, and distinct cervical lymphadenopathy. The laboratory test for tuberculosis and Human Immunodeficiency Virus (HIV) infection revealed negative. The individual was suspected of brucellosis due to his occupational thrust and endemicity of brucellosis in this region and tested positive by Rose Bengal Precipitation Test (RBPT) and Standard Agglutination Test (SAT). He was treated with doxycycline and rifampicin for 6 weeks and resolved from infection after treatment. Human brucellosis is the tip of the iceberg for animal brucellosis and to identify the source of infection, one health strategy was applied and identified the sheep which he was treating for dystocia as a source of infection. Further investigation revealed a higher prevalence of $21.42 \%$ among small ruminants in his working region by serological tests viz. RBPT, SAT, and I-ELISA. By this case report and investigation, we emphasize, Human brucellosis along with the high prevalence of animal brucellosis warrants an integrated approach in the prevention and control of brucellosis.
\end{abstract}

fever, fatigue, malaise, chills, sweats, headaches, myalgia, arthralgia and weight loss (Mantur et al., 2007). It also affects multiple organs including the bones, joints, heart, lungs, central nervous system, kidneys, liver, spleen and testes (Varona et al., 2002). Brucellosis has been more prevalent in the Mediterranean region, the Middle East, Central Asia, and parts of Latin America, making it a global problem (Sancho et al., 2015). In India, prevalence of brucellosis in humans varies between from 0.8 to $26.6 \%$ in different states (Mangalgi et al., 2015) and 
Prevalence of brucellosis ranging from 2.26 to $34 \%$ was reported among veterinarians and para-veterinarians from various parts of India (Shome et al., 2017). In animals, prevalence of the disease ranging from $6.5 \%$ to $16.4 \%$ in different species of livestock since first reported in India during the year 1887(Singh et al., 2015). The occurrence of human cases can be one of the first indicators of the presence of disease in the animal population, since the prevention of human brucellosis cannot be achieved without the control of the disease in the animals, so "One World, One Health" strategy is the need of the hour paradigm in control of brucellosis (Sancho et al., 2015; Plumb et al., 2013).

To our knowledge, this is the first case study applied one health approach in investigation of human brucellosis and identified the possible source of infection with the aim of prevention and control of brucellosis.

\section{Case report and its investigation}

A 31 year old male veterinary practitioner suffered from high fever, night sweats, chills, myalgia, tiresomeness, tremors, back pain with distinct left cervical lymph node enlargement for one week. Consulting the physician, he was examined with painful cervical lymphadenopathy measuring $1.5 \times 2$ $\mathrm{cm}^{2}$. Further, physical examination found no other adenopathies, facial / oral inflammatory lesion and respiratory problems. Initially, he was treated with cefixime - oflaxacin regimen for 5 days, but on and off symptoms persisted. Consequently, physician ordered for Fine Needle Aspiration Cytology (FNAC), Acid fast staining with aspirate, Tuberculin skin test (TST) and Serological assay to rule out Tuberculosis and HIV respectively. Fine needle aspiration had whitish aspirate and microscopically had polymorphous lymphocytes, plasma cells, histiocytes, macrophages and epithelioid cell granulomas. Staining of aspirate was negative for Acid fast bacilli and also individual is negative for TST. The serologic test ELISA was performed for HIV, which was also negative. Hematological parameters were within normal range. The patient was psychologically depressed due to the persistent clinical symptoms. Patient consulted our department about his conditions. Since he had animal contact regularly, we suspected for brucellosis among various zoonotic diseases, due to his occupational thrust and endemicity of brucellosis in this region. He was tested for brucellosis and found positive by RBPT performed by commercial Brucella abortus antigen (IVRI, Izatnagar) and SAT performed by suspension of B.abortus strain 99 (IVRI, Izatnagar) with the titre of 1: 640. Polymerase Chain Reaction from sera found to be negative. To know the possible source of infection, retrospective investigation revealed he had treated a cow for retained fetal membranes and relieved sheep from dystocia with dead fetus within 15 days. He also recollected that while removing the fetal membranes from the sheep, there was spillage on to his face in spite of taking utmost care in the field conditions.

Sera were collected from both cow and sheep were tested for Brucellosis by RBPT, SAT as per Alton et al., 1990 \& Indirect ELISA (Genomix kit). The cow was found to be negative while the sheep was positive in RBPT, SAT \& Indirect-ELISA. The patient resolved completely from clinical signs and cervical lymphadenopathy after the initiation of treatment with doxycycline (100mg) rifampicin (300 $\mathrm{mg}$ ) regimen orally twice daily for 6 weeks. To investigate the prevalence status of brucellosis in that region, serum samples from 84 animals were collected from randomly selected five flocks in the surrounding region and tested, which revealed $21.42 \%$ brucellosis prevalence rate by serological tests. 


\section{Results and Discussion}

Brucellosis poses high occupational threat to people working with farm animals, slaughterhouse workers, butchers, veterinarians, inseminators, laboratory workers, health care workers and the highest risk of brucellosis is assumed to be attracted towards individuals working with animals during abortion or parturition and during other contacts with infected animals (Karadzinska-Bislimovska et al., 2010). In this case, the veterinarian had occupational risk while handling aborted sheep and also its clinical symptoms is often difficult to differentiate infectious abortion from others in field conditions. In the present case, the patient had high fever, night sweats, chills, myalgia, fatigue and cervical lymphadenopathy. The latter is the rare form of clinical manifestation of brucellosis in India, which led to suspicion of Tuberculosis and HIV. The probable reason for cervical lymphadenopathy might be due to splashing of aborted contents into the face \& oral cavity, which corroborates with the previous report of cervical lymph nodes as selective niche for oral route of transmission (Von Bargen et al., 2015). The study conducted by Sathyanarayanan et al., 2011 and Kumar et al., 2010 did not explore the plausible source of infection for cervical lymphadenopathy in brucellosis. In the present case, the veterinarian might got infection from the sheep treated for dystocia, could be explained by experiencing symptoms of brucellosis and positive result for brucellosis by serological test in treated animal, which is also correlated by incubation period of 1-3 weeks. One health approach of human brucellosis revealed the source of infection as well as diseases prevalence status which highlights small ruminants poses a significant health risk and further efforts will be needed to control brucellosis in goats and sheep.

In conclusion, this case report of human brucellosis with rare clinical manifestation, unavailability of vaccine and high prevalence of brucellosis in animals, we emphasize occupational risk of brucellosis among veterinarian and animal handlers. Also ahead, the one health approach need to be overemphasized in diagnostic stewardship especially in occupational diseases which plays a crucial role in prevention and control of brucellosis in humans.

\section{References}

Acha PN, Szyfres B. 2011. Zoonoses and communicable diseases common to man and animals. In: Pan American Health Organization. doi:10.1590/ s1135-57272005000300 012.

Alton GG, Duncan JR and Nielsen K, 1990. Animal Brucellosis. Boston: P. 383409.

Corbel MJ. 2006. Brucellosis in humans and animals. WHO Libr Cat Publ Data., 188.

Karadzinska-Bislimovska J, Minov J, Mijakoski D, Stoleski S, Todorov S. 2010. Brucellosis as an occupational disease in the republic of macedonia. Maced J Med Sci., 3(3):251-256.

Kumar GA, Nath TV, Yasoda M, Asha A, Kumar AA. 2012. A clinicoetiological study of cervical lymphadenopathy in children with special reference to ultrasonography. $\mathrm{J}$ Clin Exp Investig., 1(2): 8-11.

Mangalgi S, Sajjan AG, Mohite ST, Kakade S V. 2015. Serological, clinical, and epidemiological profile of human brucellosis in rural India. Indian J Community Med., 40(3): 163-167.

Mantur B, Amarnath S, Shinde R. 2007. Review of clinical and laboratory features of human brucellosis. Indian J Med Microbiol., 25(3): 188-202.

Plumb GE, Olsen SC, and Buttke D. Brucellosis. 2013. 'One Health' challenges and opportunities. Revue Scientifiqueet

Technique 
(International Office of Epizootics)., 32(1): 271-278.

Sancho MP, Seco TG, Domínguez L and Álvarez J. Control of Animal Brucellosis. 2015. The Most Effective Tool to Prevent Human Brucellosis, Updates on Brucellosis. In: Updates on Brucellosis. Intech open., P. 203245.

Sathyanarayanan V, Razak A, Saravu K, Ananthakrishna SB, Mukhyprana Prabhu M, Vandana KE. 2011. Clinical profile of brucellosis from a tertiary care center in southern India. Asian Pac J Trop Med., 4(5): $397-$ 400.

Shome R, Kalleshamurthy T, Shankaranarayana PB, Giribattanvar $\mathrm{P}$, Chandrashekar N, Mohandoss N, et al., 2017. Prevalence and risk factors of brucellosis among veterinary health care professionals. Pathog Glob Health., 111(5): 234-239.

Singh BB, Dhand NK, Gill JPS. 2015. Economic losses occurring due to brucellosis in Indian livestock populations. Prev Vet Med., 119(3-4): 211-215.

Varona JF, Guerra JM, Guillén V, Guillén S, Menassa A, Palenque E. 2002. Isolated cervical lymphadenopathy as unique manifestation of Brucellosis. Scand J Infect Dis., 34(7): 538-540.

Von Bargen K, Gagnaire A, Arce-Gorvel V, De Bovis B, Baudimont F, Chasson L, et al., 2015. Cervical lymph nodes as a selective niche for brucella during oral infections. PLoS One., 10(4): 1-26.

\section{How to cite this article:}

Sundar, A., S. Rajagunalan, S. Malmarugan, R. Sangameswaran and Sinha, D.K. 2020. One Health Approach in Investigation of Human Brucellosis: A Case Report and its Investigation. Int.J.Curr.Microbiol.App.Sci. 9(12): 718-721. doi: https://doi.org/10.20546/ijcmas.2020.912.086 